\title{
Influence of high-latitude geomagnetic pulsations on recordings of broadband force-balanced seismic sensors
}

\author{
E. Kozlovskaya and A. Kozlovsky \\ Sodankylä Geophysical Observatory of the University of Oulu, Tähteläntie 62, 99600 Sodankylä, Finland \\ Correspondence to: E. Kozlovskaya (elena.kozlovskaya@oulu.fi) \\ Received: 25 January 2012 - Published in Geosci. Instrum. Method. Data Syst. Discuss.: 16 March 2012 \\ Revised: 26 June 2012 - Accepted: 5 July 2012 - Published: 17 August 2012
}

\begin{abstract}
Seismic broadband sensors with electromagnetic feedback are sensitive to variations of surrounding magnetic field, including variations of geomagnetic field. Usually, the influence of the geomagnetic field on recordings of such seismometers is ignored. It might be justified for seismic observations at middle and low latitudes. The problem is of high importance, however, for observations in Polar Regions (above $60^{\circ}$ geomagnetic latitude), where magnitudes of natural magnetic disturbances may be two or even three orders larger. In our study we investigate the effect of ultra-low frequency (ULF) magnetic disturbances, known as geomagnetic pulsations, on the STS-2 seismic broadband sensors. The pulsations have their sources and, respectively, maximal amplitudes in the region of the auroral ovals, which surround the magnetic poles in both hemispheres at geomagnetic latitude (GMLAT) between $60^{\circ}$ and $80^{\circ}$. To investigate sensitivity of the STS-2 seismometer to geomagnetic pulsations, we compared the recordings of permanent seismic stations in northern Finland to the data of the magnetometers of the IMAGE network located in the same area. Our results show that temporary variations of magnetic field with periods of 40-150 s corresponding to regular Pc4 and irregular Pi2 pulsations are seen very well in recordings of the STS-2 seismometers. Therefore, these pulsations may create a serious problem for interpretation of seismic observations in the vicinity of the auroral oval. Moreover, the shape of Pi2 magnetic disturbances and their periods resemble the waveforms of glacial seismic events reported originally by Ekström (2003). The problem may be treated, however, if combined analysis of recordings of co-located seismic and magnetic instruments is used.
\end{abstract}

\section{Introduction}

At present, most of the broadband (BB) seismic sensors are designed using the so-called force-balanced principle. The force-balance principle was proposed in the sixties of the 20th century (Block and Moore, 1966), originally for gravimeters. In the eighties, Wielandt and Streckeisen (1982) applied this principle to construct high-performance, broadband seismic sensor STS-1. Later, the same principles were used in design of a compact, 3-component broadband Streckeisen STS-2 seismometer. Nowadays, this seismometer is one of the most popular and reliable sensors in seismological studies.

In conventional passive seismometer, the inertial force produced by a seismic ground motion deflects the mass from its equilibrium position, and the displacement or velocity of the mass with respect to the instrument casing is then converted into an electric signal. A force-balance sensor reacts to the ground motion in the same manner, but the inertial force acting at the casing of the instrument in such a sensor is compensated by an additional electromagnetic restoring force acting on the mass so that the seismic mass moves as little as possible with respect to the instrument casing.

It is known that seismic broadband force-balanced sensors are sensitive to variations of surrounding magnetic field (Wielandt, 2002a). For instance, Forbriger (2007) reported about a signature of the magnetic storm on 31 March 2001, which was clearly observed in the recordings of the Streckeisen STS-2 seismometers at the German Regional Seismic Network (GRSN).

However, besides the magnetic storm there exists a number of other geomagnetic disturbances of various time scales, which are briefly summarized in Table 1 (for more details 
Table 1. Temporal scales of variations of geomagnetic field and seismic signals.

\begin{tabular}{lll}
\hline Magnetic variations & Time scales (order of) & Seismic signals \\
\hline Regular & & \\
\hline Annual & $1 \mathrm{yr}$ & - \\
The Sun rotation & 27 days & - \\
Diurnal & 24 and $12 \mathrm{~h}$ & Earth tides \\
\hline Disturbances & & \\
\hline Magnetic storm & $10-100 \mathrm{~h}$ & \\
Substorm & $0.5-3 \mathrm{~h}$ & \\
Special events (SI, SFE*) and PC disturbances & $10-30 \mathrm{~min}$ & $1-1000 \mathrm{~s}$ \\
Geomagnetic pulsations & & Regional and teleseismic earthquakes, slow earthquakes, \\
& & glacial earthquakes, Earth hum, Earth free oscillations \\
\hline
\end{tabular}

* Solar Flare Effect is due to the increases of dayside ionospheric conductivity caused by the X-rays associated with solar flares.

see, e.g. Parkinson, 1983). Regular variations of geomagnetic field are associated with the Earth and Sun rotations. From them, diurnal variations with magnitudes of the order of $100 \mathrm{nT}$ might create problems for observations of the Earth tides, but this problem has not been investigated, to our knowledge.

The other magnetic variations referred to as magnetic disturbances (except solar flare effects, SFE) are generated due to the solar wind impact on the Earth's magnetosphere. Some of them are immediate responses to changes of the solar wind (like sudden impulses (SI) and magnetic storms) or the interplanetary magnetic field (IMF). The latter are manifested in the open polar caps (PC) which are located above $80^{\circ}$ geomagnetic latitude and directly connected with the IMF by highly conducting magnetic field lines. The substorms (discussed below in Sect. 2.1) and geomagnetic pulsations (described in details in Sect. 3) are more complex consequences of the solar wind - magnetosphere interactions. As one can see in Table 1, geomagnetic pulsations are of the same time scales as many of seismic signals and, hence, they potentially may interfere seismic observations.

In practice, effects of geomagnetic field on recordings of BB seismic sensors are usually ignored. It might be reasonable for seismic observations at middle and low latitudes. However, this problem may be of high importance for observations in Polar Regions (above $60^{\circ}$ geomagnetic latitude), where magnitudes of natural magnetic disturbances may be two or even three orders larger.

The main target of the present paper is to draw attention of the seismological community to the problem of influence of natural magnetic disturbances in high latitudes on seismic records produced by $\mathrm{BB}$ seismic sensors and suggest recommendations for accounting these effects. In Sect. 2 we consider an example and discuss reasons for why broadband seismometers can be sensitive to magnetic disturbances. In Sect. 3 we give a short review of natural magnetic disturbances to indicate in which regions and to which extent mag- netic effects should be accounted for. In Sect. 4 we analyze the effect of typical Pc4 and Pi2 pulsations on recordings of glacial earthquakes originating from outlet glaciers in Greenland. In Sects. 5 and 6 we discuss some practical problems of seismic observations in high latitudes and suggest how the effect of geomagnetic pulsations in seismic recordings could be minimised.

\section{Sensitivity of force-balanced seismometers to magnetic disturbances}

\subsection{Example}

Effects of natural magnetic disturbances on seismic recordings may be significant. As an example, we consider seismic and magnetic data obtained at the Sodankylä Geophysical Observatory (see map in Fig. 1). The Observatory operates the SOD magnetometer station that is a part of the International Monitor for Auroral Geomagnetic Effects (IMAGE) magnetometer network (http://www.ava.fmi.fi/image/ index.html) and the SGF seismic station that is a part of the permanent Northern Finland Seismological Network (http:// www.oulu.fi/sgo-oty) equipped with the STS-2 seismometer. Geographic coordinates of the SOD station are $67.367^{\circ} \mathrm{N}$, $26.633^{\circ} \mathrm{E}$ and geographic coordinates of the SGF station are $67.442^{\circ} \mathrm{N} 26.526^{\circ} \mathrm{E}$. The seismometer is installed at a depth of $6 \mathrm{~m}$ in an iron-armed concrete vault.

The seismogram and magnetogram presented in Fig. 2 were obtained at the Sodankylä Geophysical Observatory at 20:00-23:00 UT on 10 August 2006. Shown in Fig. 2 (bottom panels) is a typical magnetic disturbance associated with a substorm (Rostoker et al., 1980). It is characterized by a negative deflection (so-called "magnetic bay") in the northern $(X)$ component of the magnetic field. Duration of the substorm was about 1 hour. Magnitude of the deflection in $X$-component is $200 \mathrm{nT}$. Disturbance of similar shape and magnitude is seen also in the vertical $(Z)$ component. The 


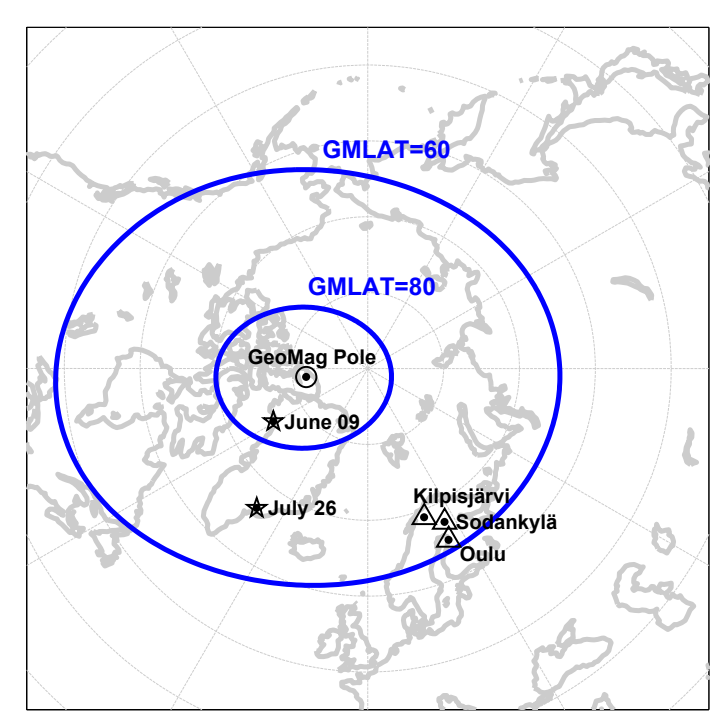

Fig. 1. A map showing position of the auroral zone in the Northern Hemisphere. Stations with co-located seismic and magnetic instruments considered in the present study are shown by triangles. Stars marked as 9 June and 26 July indicate epicentres of glacial earthquakes on 9 June and 26 July 2007 from Nettless and Ekström (2010).

disturbance in the eastern $(Y)$ component is smaller, about $50 \mathrm{nT}$ in magnitude.

At the same time, similar shape variations appeared in the seismic recording of the STS-2 seismometer (Fig. 2, top panels). The most evident is the negative deflection in vertical component showing an output signal with magnitude of the order of $10 \mu \mathrm{V}$. Horizontal components are noisier; nevertheless, variations of the output signal corresponding to the magnetic substorm are clearly seen.

The substorm was accompanied by shorter-period (about $100 \mathrm{~s}$ ) quasi-sinusoidal variations known as $\mathrm{Pi} 2$ geomagnetic pulsations. Such pulsations are linked to eigenfrequency oscillations of the magnetospheric electric currents. The first $\mathrm{Pi} 2$ event was at 20:50-21:00 UT, and the most intensive Pi2 pulsations at 21:35 UT were associated with the substorm onset. The pulsations recorded by both magnetometer and seismometer are shown in Fig. 3, where the recordings were band-pass filtered at 40-150 s. Here and throughout we use the Butterworth 3-order band-pass filter. One can see very clear signatures of the magnetic pulsations in the recording of the vertical component of the seismometer. In addition, a noticeable effect is seen in the northward component at 21:35-21:50 UT (roughly, $100 \mu \mathrm{V}$ correspond to $20 \mathrm{nT}$ ).

The correspondence between magnetic pulsations recorded by the magnetometer and the STS-2 seismometer is illustrated in Fig. 4 in more detail, where the enlarged seismic (solid curves) and magnetic (dashed grey curves) records at 21:20-22:00 UT are overlapped. The top panel shows voltage in the seismometer output and the middle and bottom panels show ground velocity and acceleration, respectively.
In order to find the ground velocity $\hat{V}(\omega)=\hat{U}(\omega) / \hat{T}(\omega)$ and the ground acceleration $\hat{a}(\omega)=i \omega \hat{V}(\omega)$, the output signal was de-convolved with the transfer function of the STS-2 seismometer,

$\hat{T}(\omega)=\frac{G \omega^{2}}{\omega_{0}^{2}-\omega^{2}+2 i h \omega_{0} \omega}$,

where $G=1500 \mathrm{Vs} \mathrm{m}^{-1}$ is a generator constant, $\omega=2 \pi f$ is the angular frequency, $\omega_{0}=2 \pi / 120 \mathrm{~s}$ is the angular eigenfrequency of the STS-2 and $h=0.707$ specifies its damping.

In the present study we used magnetic field data from fluxgate magnetometers with flat amplitude response and zero phase shift for frequencies of $0.1 \mathrm{~Hz}$ and below. That is why no correction for the instrument response was necessary for the range of periods corresponding to geomagnetic pulsations.

Figure 4 shows a good correlation, with the correlation coefficient of 0.72 , between the apparent acceleration and the magnetic field variations. It is necessary to remember, however, that positive direction of the geomagnetic field is conventionally downward in the Northern Hemisphere, whereas the positive direction of the ground motion is conventionally upward. For accounting for these different conventions we used reverse direction of the $Z$-axis for the velocity and acceleration shown in Fig. 4. Due to these different conventions, we got negative correlation and regression coefficients and $180^{\circ}$ phase shift between vertical components of the magnetic field and ground acceleration.

The amplitude of the apparent ground acceleration due to influence of geomagnetic pulsations is higher than the NLNM (New Low Noise Model, Peterson, 1993) in the frequency range under consideration. On average, magnetic variation with the amplitude of $1 \mathrm{nT}$ results in apparent acceleration of about $0.17 \mathrm{~nm} \mathrm{~s}^{-2}$. This dependence is presented in Fig. 5 in more detail, where Fig. 5a and b show amplitude spectra of the simultaneous magnetic and seismic acceleration signals, respectively. In Fig. 5c we show the seismicto-magnetic amplitude ratio $\left(K_{z z}\right)$, calculated for the frequencies at which amplitudes of magnetic signal exceed a noise level of $0.2 \mathrm{nT}$. One can see that the ratio tends to increase with the frequency, from $0.1 \mathrm{~m} \mathrm{~s}^{-2} \mathrm{~T}^{-1}$ at $5 \mathrm{mHz}$ to $2.5 \mathrm{~m} \mathrm{~s}^{-2} \mathrm{~T}^{-1}$ at $15 \mathrm{mHz}$. This tendency is illustrated by the dashed line in Fig. 5c, which represents a linear dependency with a regression coefficient of $16 \mathrm{~m} \mathrm{~s}^{-1} \mathrm{~T}^{-1}$.

\subsection{Why seismometers sense magnetic field}

A simplified scheme for the STS-2 seismometer is shown in Fig. 6 (adapted from Streckeisen, 1995). Displacement of the mass $(M)$ relative to the instrument housing is detected by a capacitive displacement transducer $(K)$ and converted to an electric signal that is transmitted to the feedback coil $(L)$. A magnetic force appears due interaction of the current in the moving coil with the field of a permanent magnet. This force restores position of the mass relative to the instrument 
Aug. 10, 2006, Sodankyla STS-2 seismometer output (low-pass filtered at period 150s)
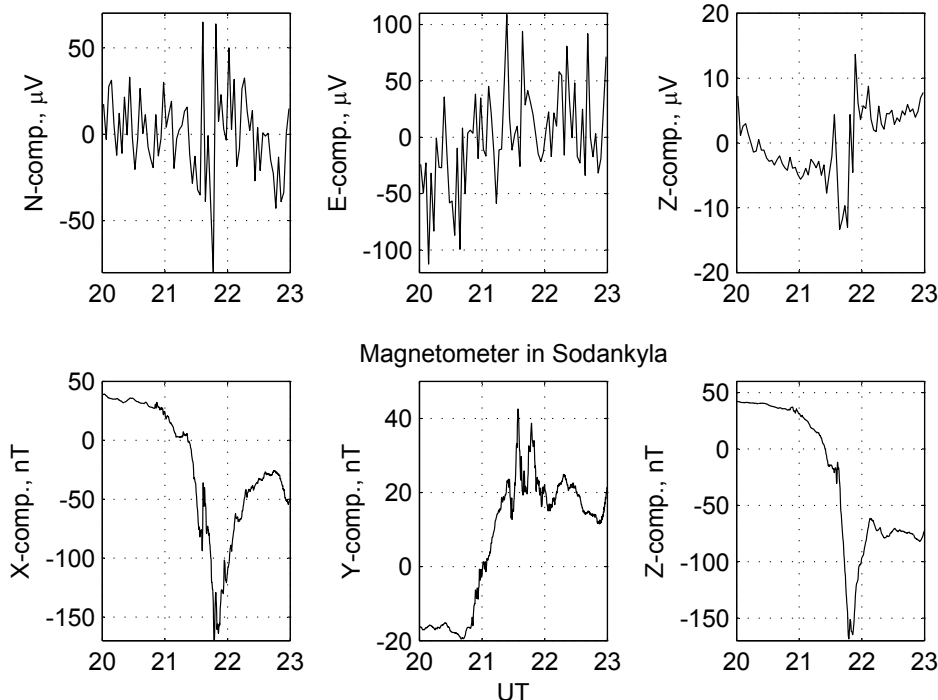

Fig. 2. An example of magnetic substorm recorded by co-located magnetometer and STS-2 seismometer in Sodankylä. Top panels show the 3-components (north, east, and vertical) of the seismometer output. The data were low-pass (at 150s) filtered. Bottom panels present variations in the corresponding three components $(X, Y$, and $Z$, respectively) of the magnetic field.
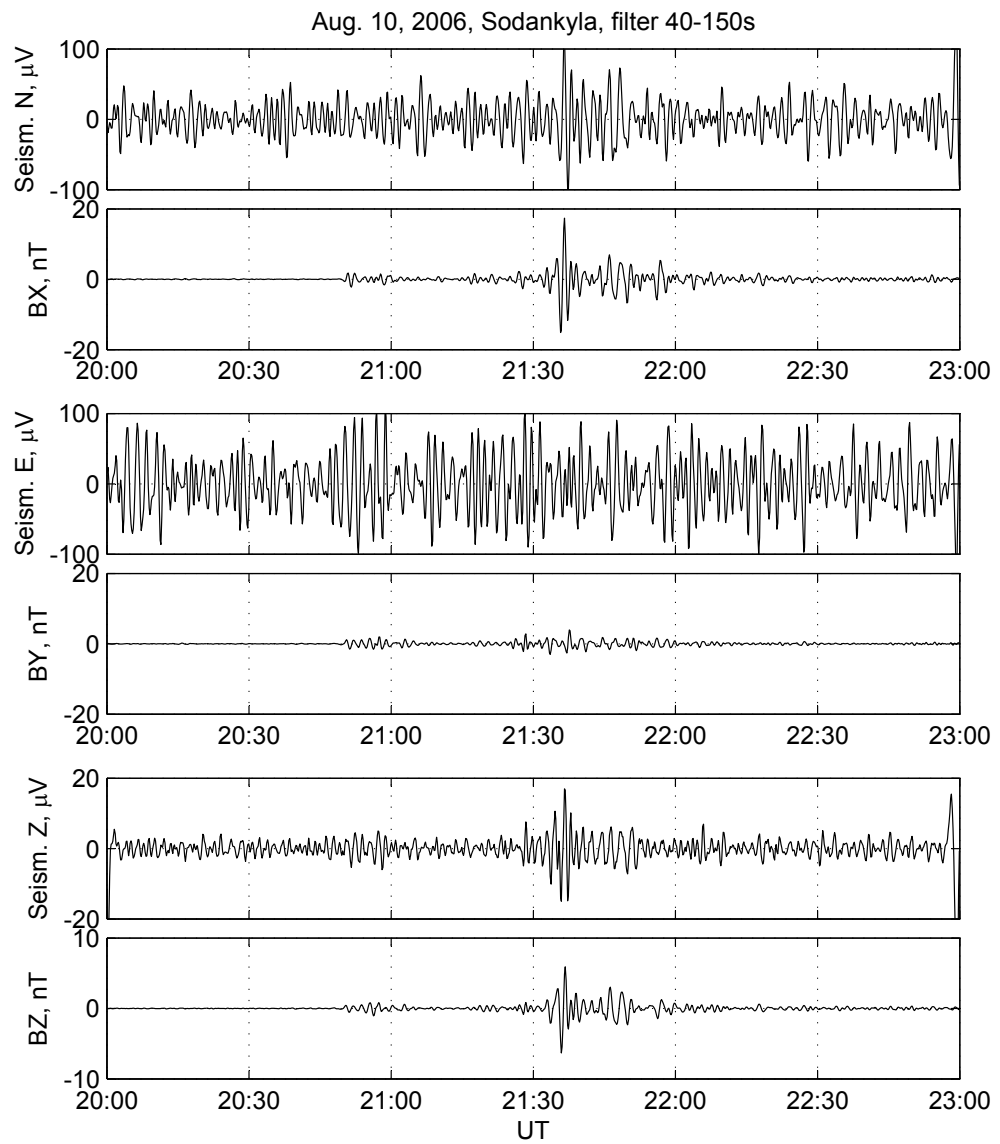

Fig. 3. An example of Pi2 geomagnetic pulsations during magnetic substorm recorded by co-located magnetometer and STS-2 seismometer in Sodankylä. The 3-components (north, east, and vertical) of the seismometer output and corresponding components of magnetogram are filtered by the same band-pass filter at $40-150 \mathrm{~s}$. 

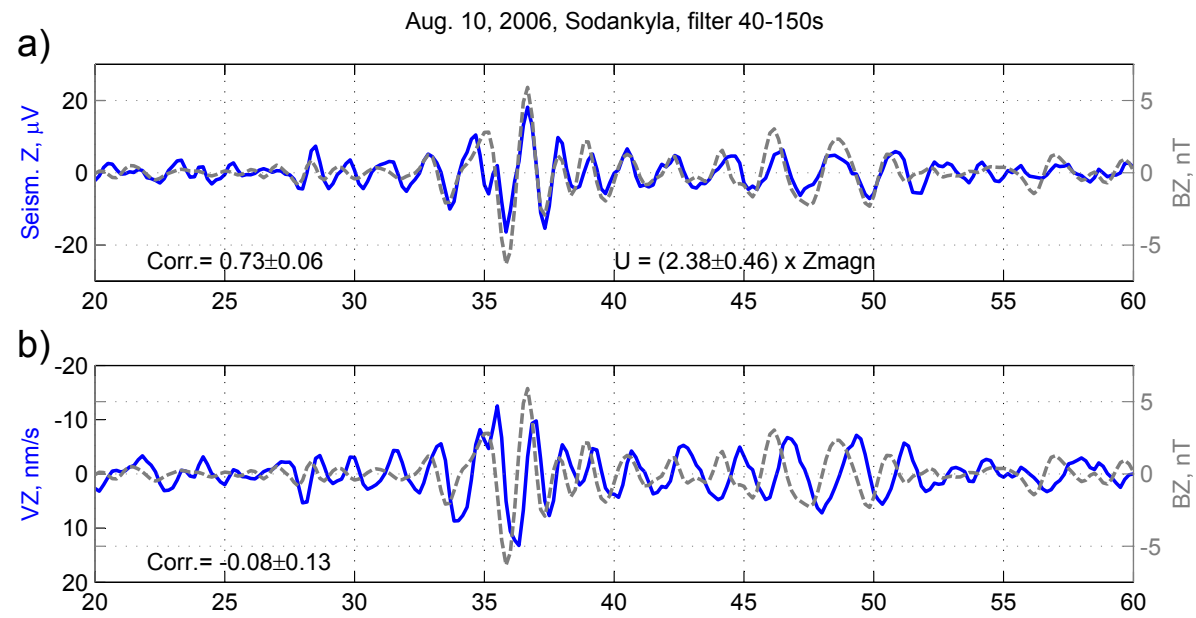

c)

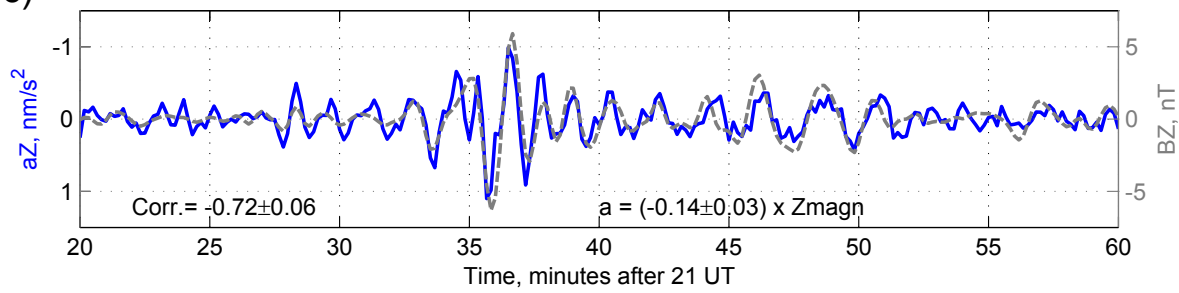

Fig. 4. Comparison of shape of signal of Pi2 geomagnetic pulsations recorded by the magnetometer in Sodankylä to the shape of the same event recorded by the STS-2 seismometer: (a) shows comparison of the magnetometer signal to the voltage at the seismometer output; (b) shows comparison of the magnetometer signal to ground velocity; (c) shows comparison of the magnetometer signal to ground acceleration.
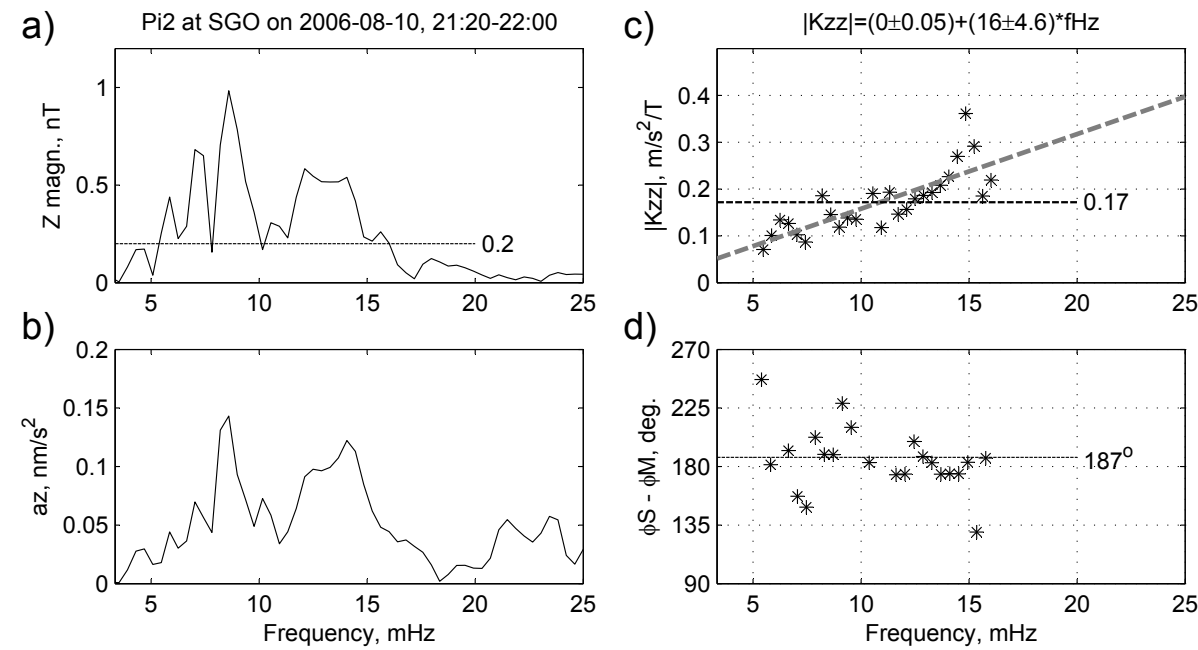

Fig. 5. (a) and (b) show amplitude spectra of the simultaneous magnetic and seismic acceleration signals, respectively; (c) shows the seismicto-magnetic amplitude ratio $\left(K_{z z}\right)$, calculated for the frequencies at which amplitudes of magnetic signal exceed a noise level of $0.2 \mathrm{nT}$; (d) shows the phase shift (near $180^{\circ}$ ) between the seismic and magnetic signals.

housing. Thus, the inertial force is compensated (or "balanced") with the electrically-generated force on the mass to keep the motion of the mass with respect to instrument housing as small as possible. Some small motion is still required, however, because otherwise the inertial force could not be observed. Ultimately, the electric current that generates the feedback force is proportional to the force and thus is a measure of the acceleration applied to the mass. The voltage produced by this current in the integration part of the feedback (capacitor $C$ ) is proportional to the ground velocity and is 


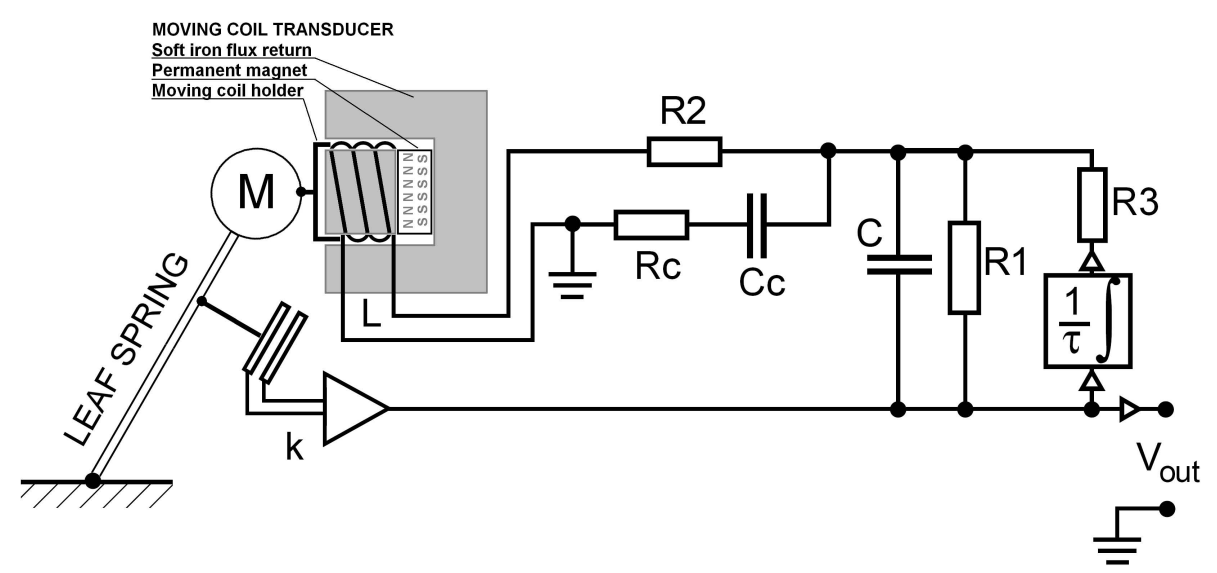

Fig. 6. A simplified scheme of the STS-2 velocity broadband seismometer (force-balanced) (per Streckeisen, 1995; Wielandt, 2002a). Mass $(M)$ displacement relative to the instrument housing is detected by a capacitive displacement transducer $(K)$ and converted to an electric signal that is transmitted to the feedback coil $(L)$. $R$ denote resistors, $C$ denote capacitors. Output voltage is denoted as Vout.

used as an output signal of the seismometer (Wielandt and Streckeisen, 1982).

Per Wielandt (2002b), it is usually believed that broadband seismometers are sensitive to magnetic fields because all thermally-compensated spring materials are slightly magnetic. Following this idea, Forbriger (2007) considered three different physical mechanisms which might contribute to the sensitivity of the suspension to the magnetic field: (1) a remanently magnetized spring may experience a torque in a magnetic field like a compass-needle does; (2) a variation in magnetization may result in magnetostriction, thus changing the geometry of the spring and disturbing the balance of the seismometer pendulum; (3) a variation in magnetization may result in a variation of the elastic modulus and thus change the suspension force applied to the seismometer pendulum. He has concluded that the compass-needle effect is likely the main mechanism which is responsible for the seismometer sensitivity to magnetic field. This effect (as well as the other two) produces an apparent acceleration of the seismic mass proportional to the magnetic field, with a frequency-independent regression coefficient. Indeed, the example presented in Fig. 4 indicates proportionality. However, in Fig. 5 one can see that the ratio tends to increase with the frequency, from $0.1 \mathrm{~m} \mathrm{~s}^{-2} \mathrm{~T}^{-1}$ at $5 \mathrm{mHz}$ to $2.5 \mathrm{~m} \mathrm{~s}^{-2} \mathrm{~T}^{-1}$ at $15 \mathrm{mHz}$. This frequency dependence was not explained in the frame of the needle effect.

For explaining the frequency dependency we may suggest one more physical mechanism which, to our knowledge, was usually ignored. A key point is that the modern broadband seismometers use electromagnetic force transducers (actuators) in their feedback path in order to produce the movement of the proof mass with respect to the instrument housing. There exists a variety of different types of electromagnetic force transducers (see, for example, Brauer, 2006). A force transducer, in which the force is generated by currentcarrying coil moving in the static field of a permanent mag- net, is used in the STS-2 seismometer (Wielandt, 2002b). Such actuators can have a variety of topologies, but the common principle is that magnetic flux generated by the permanent magnet is directed into an airgap, where the coil is suspended, and closed through the magnetic circuit (flux return) composed of some soft ferromagnetic material (for example, steel) (Fig. 6). If the seismometer together with the feedback coil resides in the Earth's magnetic field $\boldsymbol{B}$, the additional magnetic flux through the coil due to the geomagnetic field is

$\Phi=\boldsymbol{B}_{\mathrm{c}} \cdot \boldsymbol{A}$,

where $\boldsymbol{B}_{\mathrm{c}}$ and $\boldsymbol{A}$ are the magnetic field in the coil and the area of coil, respectively. The magnetic field in the coil relates to the Earth's magnetic field measured in the air as

$\boldsymbol{B}_{\mathrm{c}}=k \boldsymbol{B}$,

where $k$ is a coefficient which depends on the magnetic permeability of materials in a vicinity of the coil. In particular, the force transducer contains soft iron elements with high permeability, so that $k$ may be of the order several thousands.

When the magnetic field is changing, the magnetic flux through the coil is changing respectively. Hence, according to the Faraday's law, a voltage (electromotive force, emf) is generated in the coil:

$U_{\mathrm{emf}}=-N \frac{\Delta \Phi}{\Delta t}$,

where $N$ is number of turns in the coil. This may affect the current in the coil and ultimately contribute to the seismometer output. For estimating the magnitude of this effect, one needs to know actual parameters of the electric circuits and the force transducer of the STS-2 seismometer. Moreover, high-permeability elements (e.g. the leaf springs made of Elinvar alloy with permeability between 50 and 350) can 
Table 2. Classification of geomagnetic pulsations.

\begin{tabular}{llll}
\hline Pulsations & $T, \mathrm{~s}$ & $f$ & Amplitudes, nT \\
\hline Pc 1 & $0.2-5$ & $0.2-5 \mathrm{~Hz}$ & $0.01-0.1$ \\
Pc 2 & $5-10$ & $0.1-0.2 \mathrm{~Hz}$ & $0.1-1$ \\
Pc 3 & $10-45$ & $22-100 \mathrm{mHz}$ & $1-10$ \\
Pc 4 & $45-150$ & $7-22 \mathrm{mHz}$ & $5-50$ \\
Pc 5 & $150-600$ & $2-7 \mathrm{mHz}$ & $50-500$ \\
Pi 1 & $1-40$ & $0.025-1 \mathrm{~Hz}$ & $0.2-1$ \\
Pi 2 & $40-150$ & $2-25 \mathrm{mHz}$ & $10-100$ \\
\hline
\end{tabular}

enormously violate the magnitude and direction of magnetic field inside the seismometer. Configuration of the disturbed magnetic field inside the seismometer and its influence on different components of seismic output signal can be estimated, in principle, if one knows precise geometry and material properties of all parts of the force transducer, leaf spring and also of other ferro- and ferrimagnetic materials inside the seismometer. The methods and computer programs for that are known (see, for example, Brauer, 2006). Having no exact information about the actual properties of materials inside the STS-2 seismometer, we are not able to present here precise qualitative estimations of the induction effect. However, we would like to draw attention of the manufactors of broadband seismometers to this problem.

\section{Natural magnetic disturbances in high latitudes}

Geomagnetic pulsations are short period (of the order of 1 to $1000 \mathrm{~s})$ fluctuations of the near-Earth magnetic field. They are signatures of the ultra-low-frequency (ULF) hydromagnetic waves which are produced by processes in the magnetosphere and solar wind (see McPherron, 2005, for review). Morphological characteristics of the pulsations have been intensively studied since the International Geophysical Year (1957-1958) and have been summarized by Troitskaya and Gul'elmi (1967) and Jacobs (1970).

Commonly accepted classification scheme for the ULF waves according to the type (continuous, $c$, and irregular, $i$ ) and period of the pulsations is given in Table 1 (Jacobs et al., 1964). Averaged amplitudes of ULF waves are illustrated in Fig. 7 (adopted from Janovsky, 1978), and typical amplitudes of the pulsations are given in Table 2. As one can see from Table 2 and Figs. 3-4, the ULF waves with periods larger than $20 \mathrm{~s}$ may have amplitudes large enough to be sensed by the STS-2 seismometer that has a flat velocity response up to $120 \mathrm{~s}$. Thus, the pulsations Pc3, 4, 5 and Pi2 may essentially affect seismic recordings.

The most intensive pulsations have their sources and, respectively, maximal amplitudes in the region of the auroral ovals which surround the magnetic poles in both hemispheres at geomagnetic latitude (GMLAT) between $60^{\circ}$ and $80^{\circ}$ (Fig. 1). Here and throughout the paper we use the

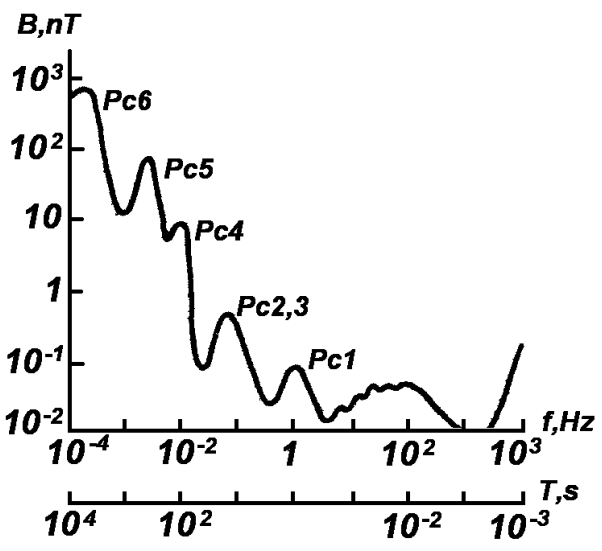

Fig. 7. Dependence of amplitude of geomagnetic pulsations on their frequencies and periods (modified from Janovsky, 1978).

corrected geomagnetic coordinate system (Gustafsson et al., 1992). Width and latitudinal position of the auroral oval depend on the level of magnetic activity and local time. In the night, the centre of the auroral oval is typically located at 65 $70^{\circ}$ GMLAT, whereas on the dayside it is at higher latitudes, around $75^{\circ}$ GMLAT.

Irregular Pi2 pulsations look like transient bursts (see Fig. 3). They are generated in the nightside in association with substorms. The substorms typically occur 3-6 times per day and last about $3 \mathrm{~h}$ (McPherron, 2005). The most intensive Pi2 pulsations occur near midnight at $65-70^{\circ}$ GMLAT, in the region of substorm onset. Here they may have amplitudes up to $100 \mathrm{nT}$; however, the amplitude decreases with the distance from the source, so that at a distance of the order of 300-500 km it may decrease down to a few nT (see, for example, Yumoto, 2001, and references therein). The Pi2 pulsations of such amplitudes may be recorded also in the middle latitudes.

Continuous pulsations $(\mathrm{Pc})$ are mostly dayside phenomena; they are generated due to the solar wind interaction with the magnetosphere. At magnetograms they look like regular quasi-sinusoidal oscillations. In practice, the Pc3 and Pc4 pulsations occur every day (Gul'elmi, 1974). In the dayside they are observed throughout the globe and have amplitudes of one to a few $\mathrm{nT}$ in middle latitudes and up to tens $\mathrm{nT}$ in the auroral latitudes around midday (Pilipenko et al., 2008). Sometimes the Pc4 pulsations are observed as very regular oscillations lasting an hour or more (so-called "Pc4 giant pulsations" or $\mathrm{Pg}$ ). A typical example of Pg pulsations is presented in Fig. 8a. Pg pulsations occur during quiet geomagnetic conditions, mainly in the early morning sector at 03:0007:00 MLT (magnetic local time), preferably in a narrow latitudinal band (approximately $63^{\circ}-68^{\circ}$ geomagnetic latitude) (Brekke et al., 1987; Chisham and Orr, 1994).

Dayside Pc5 pulsations with a rather broad spectrum have maximal amplitudes up to hundreds $\mathrm{nT}$ in the cusp region (around $75^{\circ}$ GMLAT near noon), whereas more 

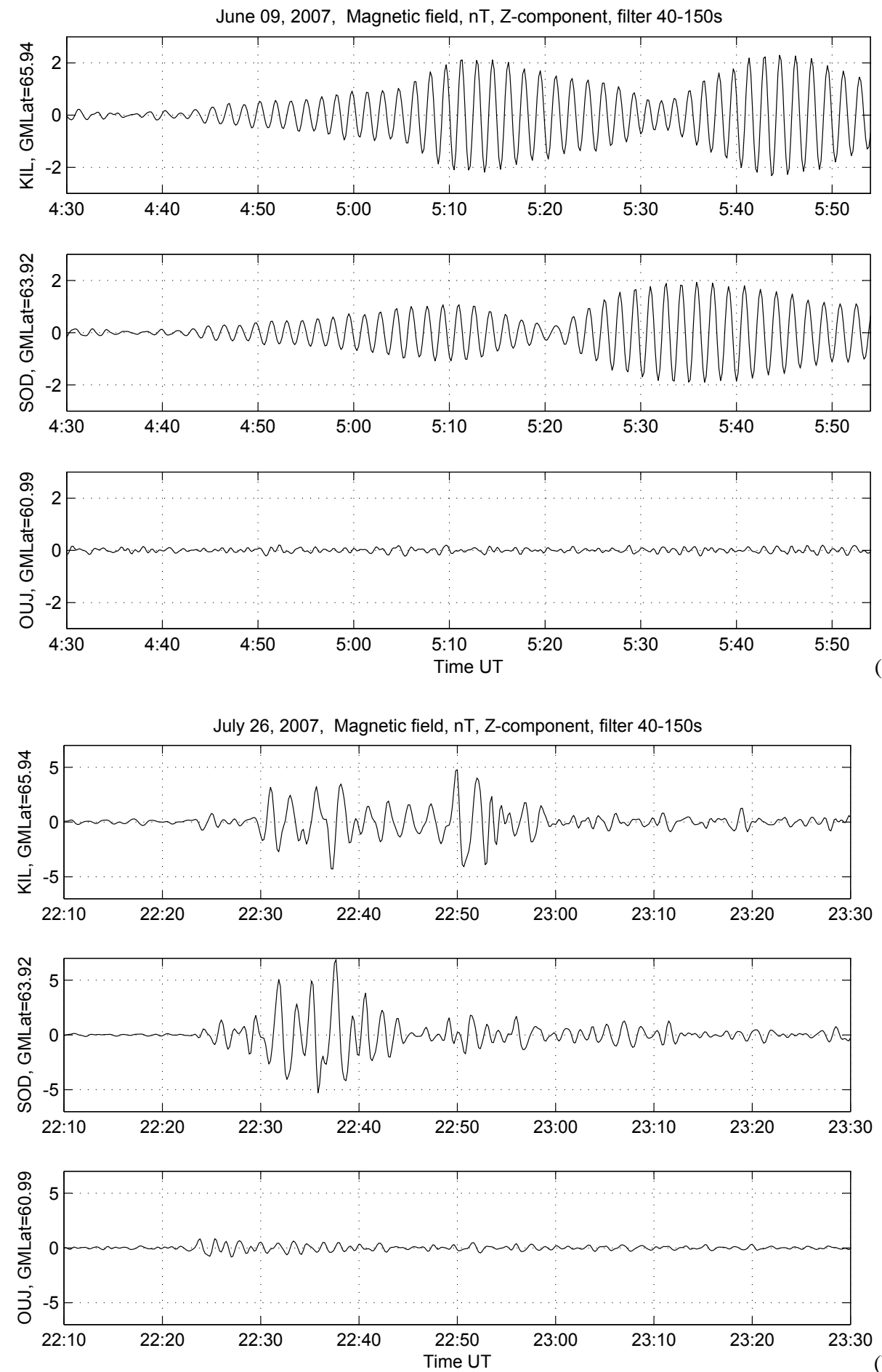

(b)

Fig. 8. (a) Geomagnetic pulsations recorded by the IMAGE magnetometers in northern Finland (only Z-component is shown). Example of Pc4 pulsations on 9 June 2007. (b) Same as (a) but for the example of Pi2 pulsations on 26 July 2007.

monochromatic Pc5 of smaller amplitude occur at auroral latitudes (around $70^{\circ}$ GMLAT) (Engebretson et al., 2006). As a rule, the most intensive pulsations occur as a transient response to sharp changes in the interplanetary parameters

Geosci. Instrum. Method. Data Syst., 1, 85-101, 2012 (the interplanetary magnetic field, the solar wind speed and plasma density).

Seismic signals from teleseismic earthquakes are typically in the frequency range of $3 \mathrm{~Hz}-3 \mathrm{mHz}$ (periods from 0.3 to $300 \mathrm{~s}$ ). This is well within the frequency range of 
geomagnetic pulsations. Thus, the high-latitude Pc4-5 pulsations may affect recordings of such events in the morning (03:00-09:00 MLT) at around 65-70 GMLAT and during daytime (06:00-18:00 LT) at around $70-75^{\circ}$ GMLAT. The Pi2 pulsations, in turn, may be the most significant at stations located close to $65-70^{\circ}$ GMLAT near midnight. In the Northern Hemisphere, the areas influenced by pulsations are northern Fennoscandia, Spitsbergen, Greenland, Northern Canada, Alaska and Northern Russia. In the Southern Hemisphere, it is Antarctica.

Generally, it is commonly known that intensity and occurrence of geomagnetic disturbances are larger during periods of high solar activity. However, some geomagnetic pulsations preferably occur during periods of quiet conditions. For instance, occurrence of Pg pulsations anti-correlates with sunspot number (Brekke et al., 1987). Indeed, the Pc4 pulsations tend to occur during lower geomagnetic activity (Troitskaya and Gul'elmi, 1967).

Thus, the influence of geomagnetic pulsations on seismic recording should be always accounted for at high latitudes, but it cannot be completely ignored at middle and low latitudes either.

\section{Influence of high-latitude geomagnetic pulsations on recordings of glacial earthquakes}

As can be concluded from Sect. 3 and Fig. 7, the period range of the most intensive geomagnetic pulsations overlaps with that of surface waves from teleseismic earthquakes. Therefore, these disturbances do not affect recordings of body waves from local, regional and teleseismic events and do not create a problem for detection of seismic events by methods based on analysis of body waves. However, they can be a problem for detection of seismic events by methods using surface waves (cf. Ekström, 2006).

One important class of such events are glacial earthquakes, originally discovered by analysis of long-period seismographs. Glacial earthquakes are events that originate from large moving glaciers in Greenland, Antarctica and Alaska and generate large-amplitude, long-period seismic waves (Ekström et al., 2003). Glacial earthquakes in Greenland showed a strong seasonality as well as a doubling of their rate of occurrence between 2000 and 2005, suggesting a link between these events and accelerating mass loss and melting of the Greenland ice sheet (Ekström et al., 2006). That is why studying glacial seismic events in Greenland and in Antarctica was one of the targets of the scientific program of the International Polar Year 2007-2009 and motivation for deployment of a number of new broadband seismic stations both in Greenland (http://glisn.info/) and in Antarctica (Wiens et al., 2008).
Glacial earthquakes from Greenland generate seismic signals depleted in high frequencies and having dominant periods between 35 and $150 \mathrm{~s}$ that are seen in seismograms as transient pulses of duration of 10-20 min (Ekström et al., 2003). As the Pc 3,4 and Pi2 pulsations have essentially the same periods, they can mask the true signals from glacial earthquakes and even result in false detections if the data of single station is used and velocity of propagation cannot be analysed.

In the following we consider two examples of geomagnetic disturbances, which were selected in such a way that they overlap in time with the signals from two glacial earthquakes in Greenland reported by Nettless and Ekström (2010). The map in Fig. 1 shows positions of the stations with co-located seismic and magnetic instruments considered in the present study (Oulu, Sodankylä, and Kilpisjärvi), the auroral zone in the Northern Hemisphere, and epicentres of two glacial earthquakes occurring on 9 June and 26 July 2007 (Nettless and Ekström, 2010).

Figure $8 \mathrm{a}$ and $\mathrm{b}$ demonstrate examples of the regular Pc4 and irregular Pi2 pulsations recorded by magnetometers of the IMAGE magnetometer network in northern Finland during the glacial earthquakes on 9 June and 26 July, respectively. The recordings were filtered by the same $40-150 \mathrm{~s}$ Butterworth 3-order band-pass filter. As can be seen, the amplitude of pulsations depends on geomagnetic latitude. Pulsations with the largest amplitudes were observed at the most northern KIL station. Clear signals are seen also at the SOD station, while the amplitude of these events at the most southern OUJ station is insignificant.

The same geomagnetic disturbances recorded by the STS2 broadband seismometers at co-located permanent seismic stations and filtered by the same $40-150 \mathrm{~s}$ bandpass filter are shown in Fig. 9a and b. As seen, the Pc4 pulsations are very pronounced at the KIF station. The pulsations can be still noticed at the SGF station, while they are very weak at the most southern OUL station. The same trend can be noticed also in the recordings of the Pi2 pulsations. Namely, they are seen very well at the most northern KIF station and they are very weak at the OUL station. The station SGF was temporarily out of operation during this event.

Figure 9a shows that the Pc4 pulsations have completely masked the signal from the glacial earthquake at the KIF station, and also increased the level of the long-period noise at the SGF station, while the signal from the glacial event can be easily recognized at the OUL station. Figure 9b demonstrates how the bandpass filtering of the Pi2 pulsations recorded by the STS-2 seismometer can produce a pseudoglacial earthquake signal at the KIF station, with the duration and periods typical for events described by Ekström et al. (2003, 2006) and Netless and Ekström (2010).

These two examples demonstrate that geomagnetic pulsations can be a serious problem for proper detection of glacial earthquakes if the stations located in the vicinity of the auroral region are used. Clear correlation between waveforms 

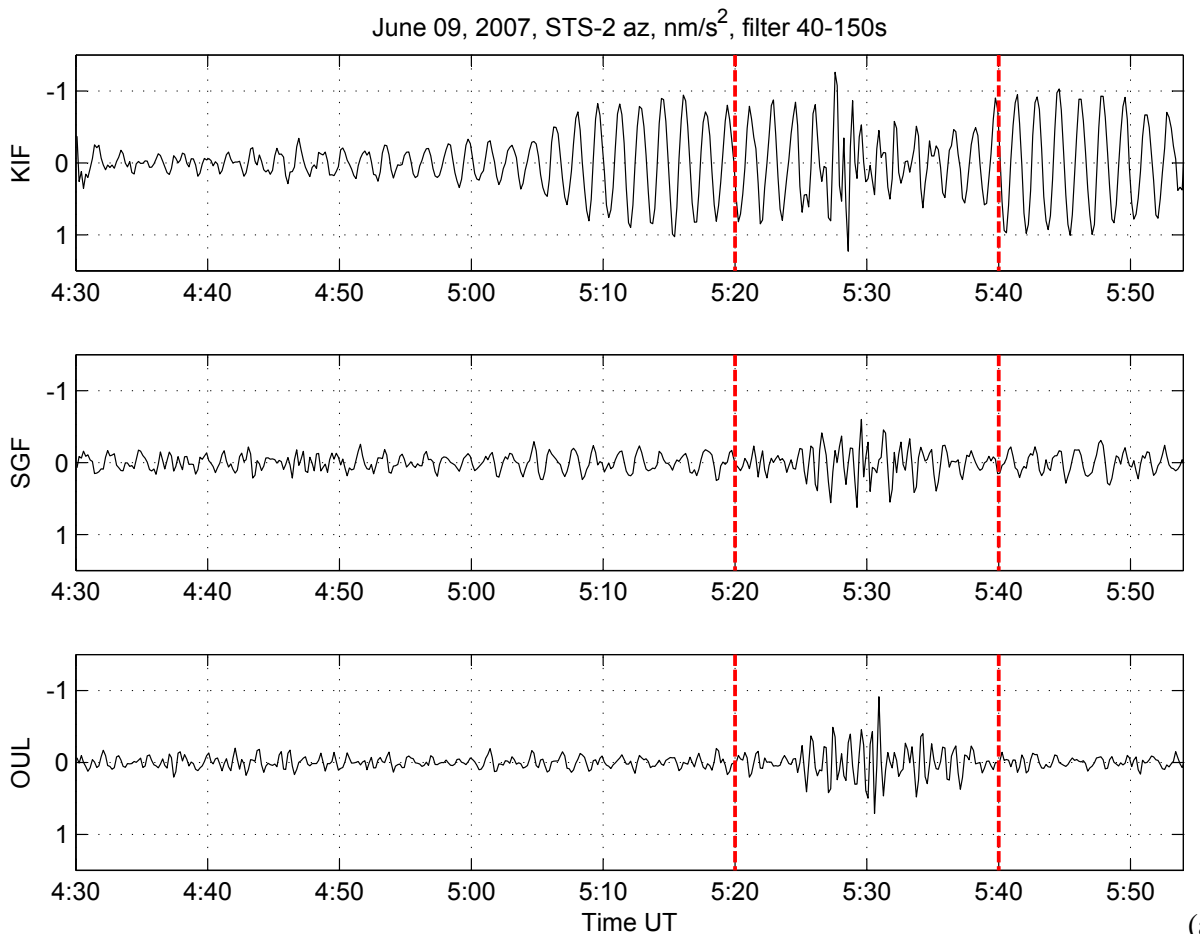

(a)
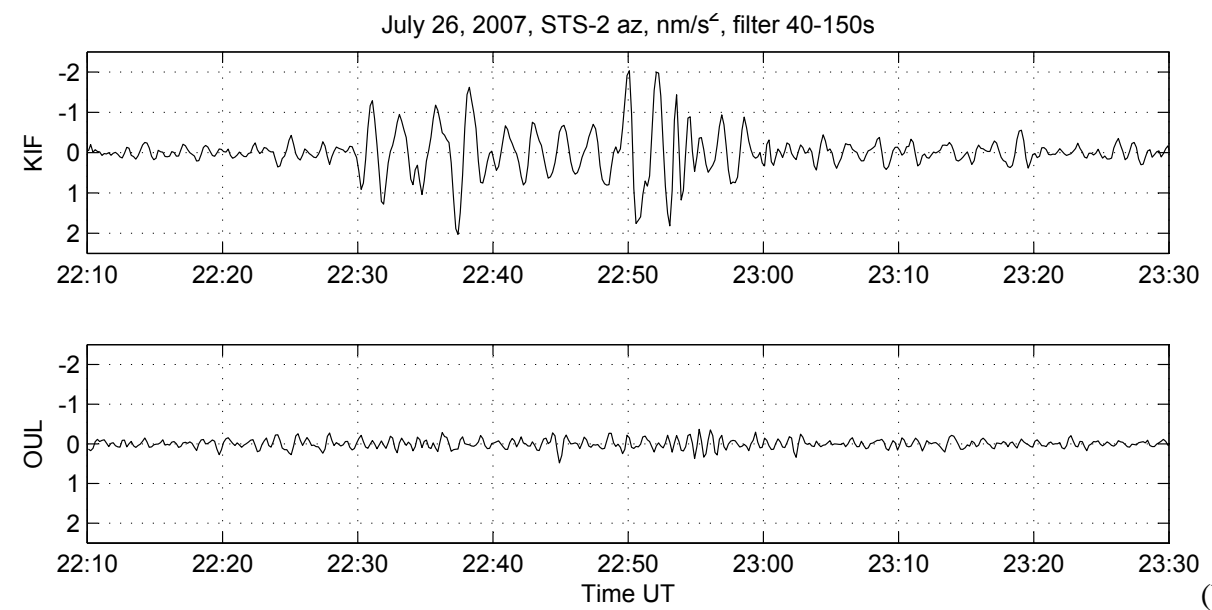

(b)

Fig. 9. (a) Geomagnetic pulsations recorded by the STS-2 seismometers at permanent seismic stations OUL, SGF and KIF for the Pc4 event on 9 June 2007. Red lines indicate time interval of glacial seismic event in Greenland (according to Nettles and Ekström, 2010). (b) Geomagnetic pulsations recorded by the STS-2 seismometers at permanent seismic stations OUL and KIF for the Pi2 event on 26 July 2007.

of geomagnetic pulsations registered by magnetometers and seismometers (Figs. 8-9) suggests, however, that comparison of recordings of co-located seismometers and magnetometers can be used to avoid misinterpretation of seismic signals and also to remove the effects of these disturbances from seismic recordings.

\section{Correlation between output of the STS-2 seismometer and magnetic disturbances}

In order to understand how the seismometer signal is affected by variations in all three components of the magnetic field, we used multi-factor linear regression analysis for the magnetic and seismic records in Kilpisjärvi. We assume that the output signal of the seismometer due to variation of surrounding magnetic field is caused by a linear combination of three factors, $B_{x}, B_{y}$, and $B_{z}$, which correspond to three components of the surrounding magnetic field $\boldsymbol{B}$. In this case 

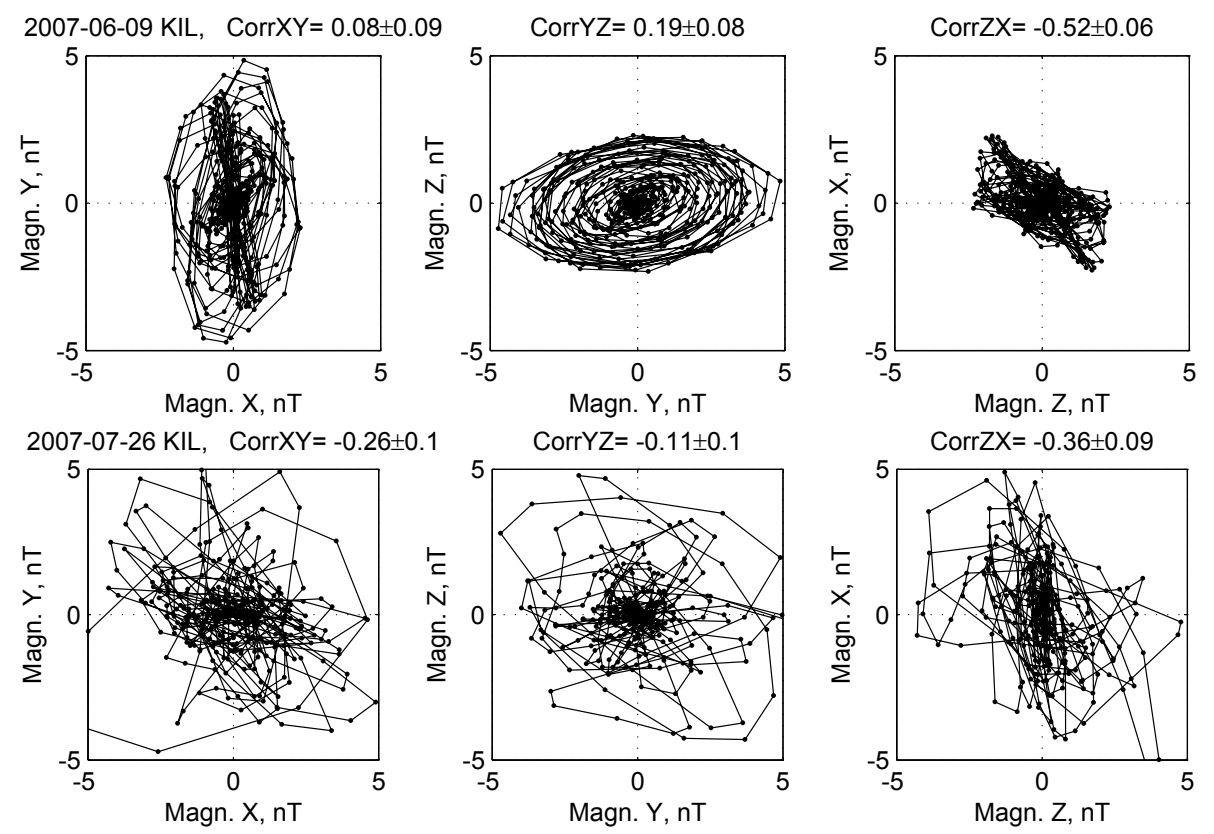

Fig. 10. Hodographs of geomagnetic pulsations Pc4 (top panels) and $\mathrm{Pi} 2$ (bottom panels) in $X Y, Y Z$, and $Z X$ planes. Correlation coefficients between the components are indicated on tops of the panels.

the apparent ground acceleration on the $Z$-component of the seismometer can be presented as:

$a_{z}=K_{x z} B_{x}+K_{y z} B_{y}+K_{z z} B_{z}$.

As can be seen in Fig. 10, there is practically no correlation between the signals in various components of magnetic field. This allows us to calculate the regression coefficients $\left(K_{x z}, K_{y z}\right.$, and $\left.K_{z z}\right)$ using the least-square minimization. The regression analysis for two disturbances are illustrated in Figs. 11a and 12a (Pc4 pulsations) and Figs. 11b and 12b (Pi2 pulsations), corresponding to the events presented above in Fig. 8a and b, respectively. In Fig. 11a and b, the top three panels show magnetic disturbances in all three components of the magnetic field, pass-filtered in the $40-150 \mathrm{~s}$ period band, and the fourth panel from the top shows corresponding acceleration output of the STS-2 seismometer $\left(a_{z}\right)$ filtered by the same filter.

Figure 12a shows the results of the multi-factor analysis for the case of Pc4 pulsations recorded in Kilpisjärvi. Each of three panels corresponds to one of the three components of the magnetic field. For instance, the left panel shows the dependence of the residual signal $a_{z x}$,

$a_{z}^{x}=a_{z}-K_{y z} B_{y}-K_{z z} B_{z}$

versus $B_{x}$. In this way, $a_{z}^{x}$ represents an estimate for the effect of the $B_{x}$ on the vertical component of the seismometer (after the effects of $B_{y}$ and $B_{z}$ have been subtracted). The other two panels show estimates for the effects of $B_{y}$ and
$B_{z}$, respectively. Straight lines represent the least-square linear fits to the data points. Figure $12 \mathrm{~b}$ shows the result of the same multi-factor analysis for the case of the $\mathrm{Pi} 2$ pulsations.

At the top of each panel, the regression coefficients are given along with the correlation coefficients between two corresponding parameters (e.g. the correlation between $B_{x}$ and the residual $a_{z}^{x}$ is given in the top of left panel). Confidence intervals for the correlation coefficients were calculated using the following formula from Nikitin (1990, p. 270):

$\delta C_{\mathrm{corr}}=t_{\gamma} \frac{1-C_{\mathrm{corr}}^{2}}{\sqrt{n}}$,

where $n$ is the number of data points and $t_{\gamma}$ is the inverse standardized normal distribution (for the $95 \%$ confidence interval, $\left.t_{\gamma}=1.96\right)$.

The results shown in Fig. 12a and b indicate that the signal in the $Z$ component of the STS- 2 seismometer is affected mainly by the $Z$ component of magnetic field, while influence of other components is minor.

Bottom panels in Fig. 11a and b show residual seismic signals after magnetic effects have been subtracted using the linear regression coefficients derived above. As can be seen, the effect of geomagnetic pulsations (in particular, of the almost linearly polarized Pc4 pulsations) was efficiently removed from the seismic recording.

Figure 13 shows amplitude spectra of the magnetic (Fig. 13a) and seismic (Fig. 13b) signals in Z-component for the cases of Pi2 (left panels) and Pc4 (right panels) 


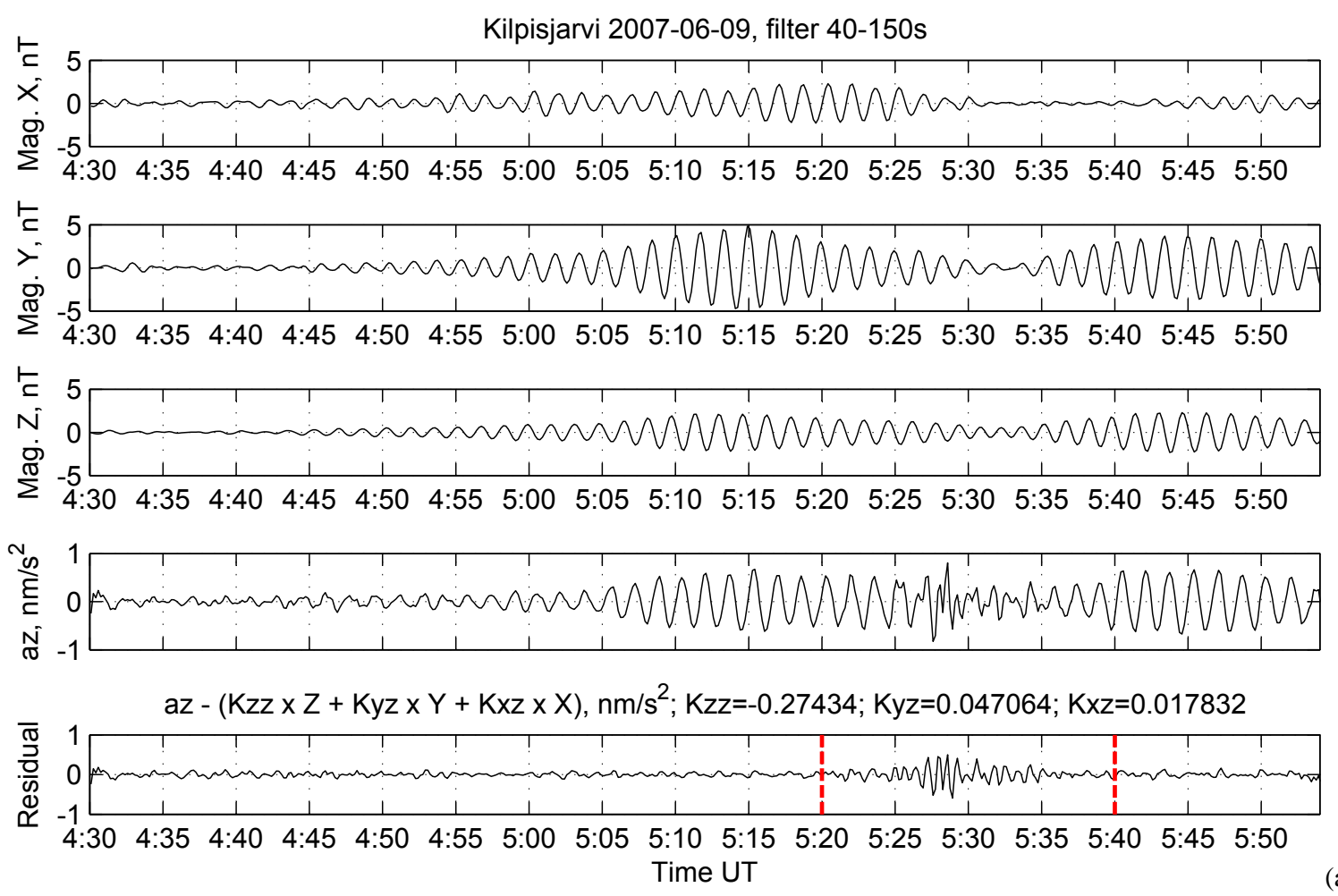

(a)

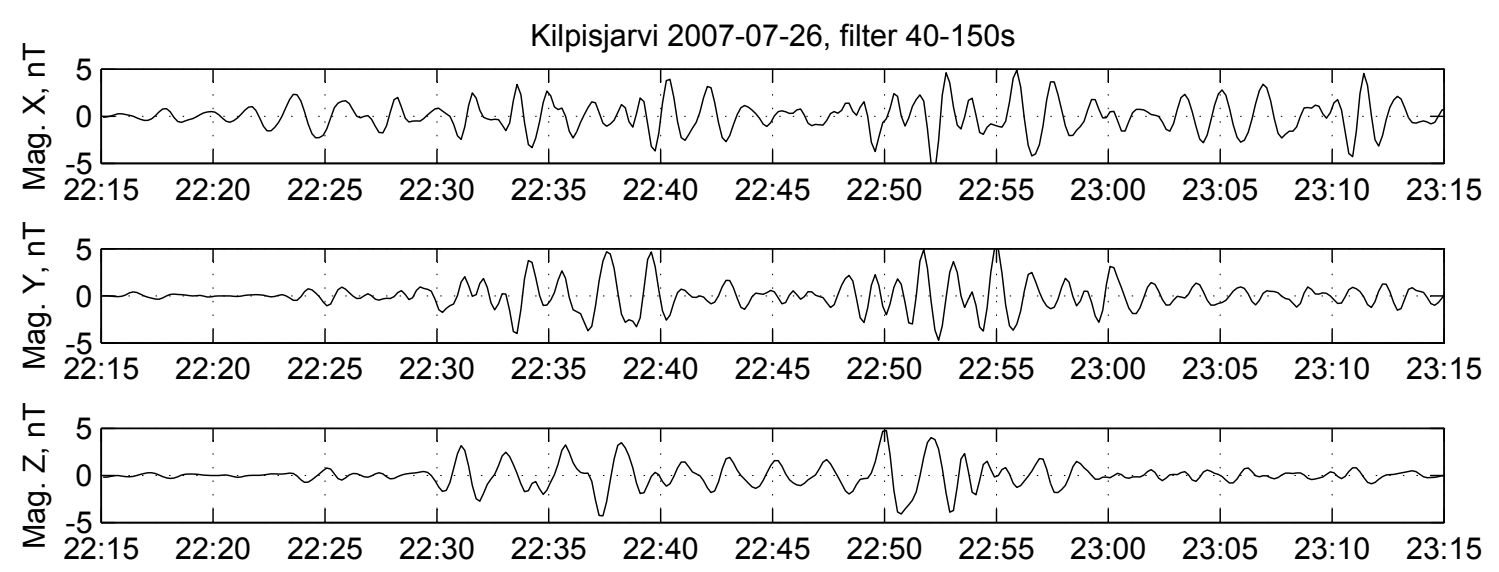

$\sum_{\substack{n \\ \text { हn }}}^{2}$

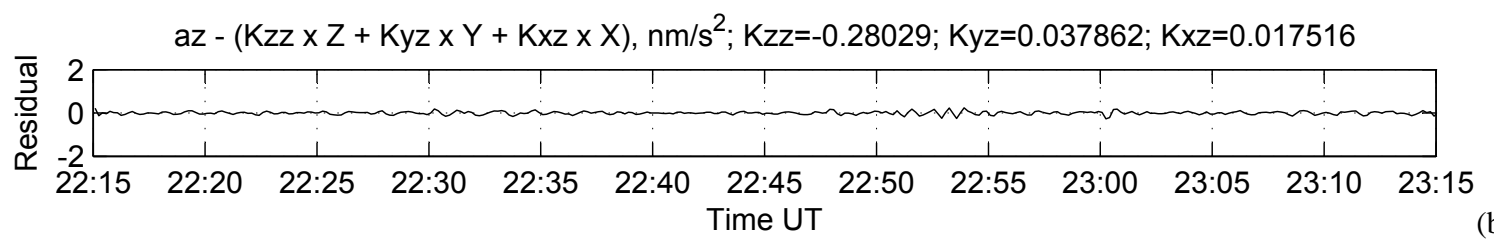

(b)

Fig. 11. (a) Case of Pc4 pulsations observed in Kilpisjärvi on 9 June 2007. Magnetic disturbances in all three components of the magnetic field (three top panels) are pass filtered in the 40-150 s period band, and seismic output $\left(a_{z}\right)$ is filtered in the same way. Bottom panels show residual seismic signals after magnetic effects being subtracted, with the linear coefficients derived from the multi-factor regression analysis. Red lines indicate time interval of glacial seismic event from Greenland (according to Nettles and Ekström, 2010). (b) Same as (a) but for the case of Pi2 pulsations observed in Kilpisjärvi on 26 July 2007. 

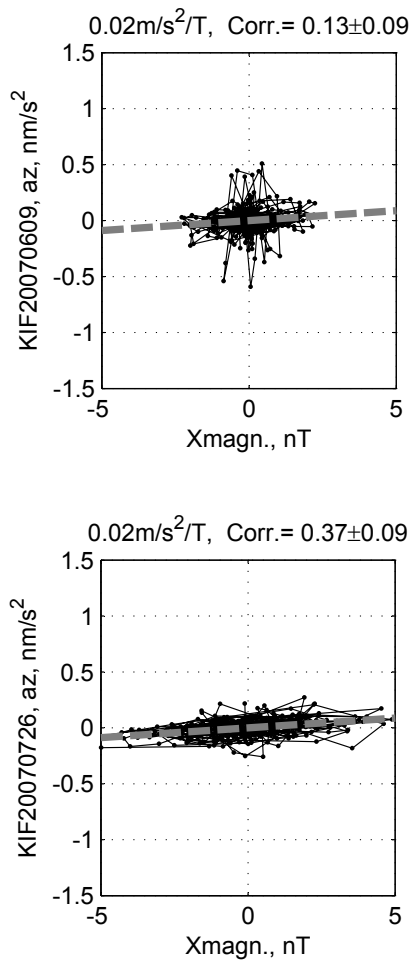
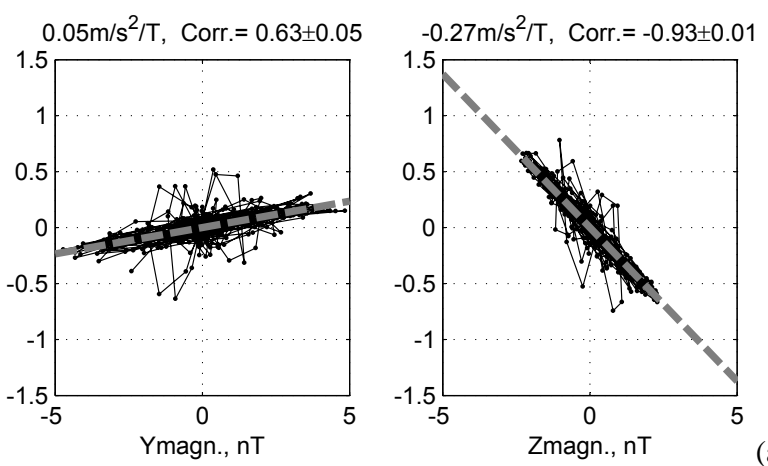

(a)
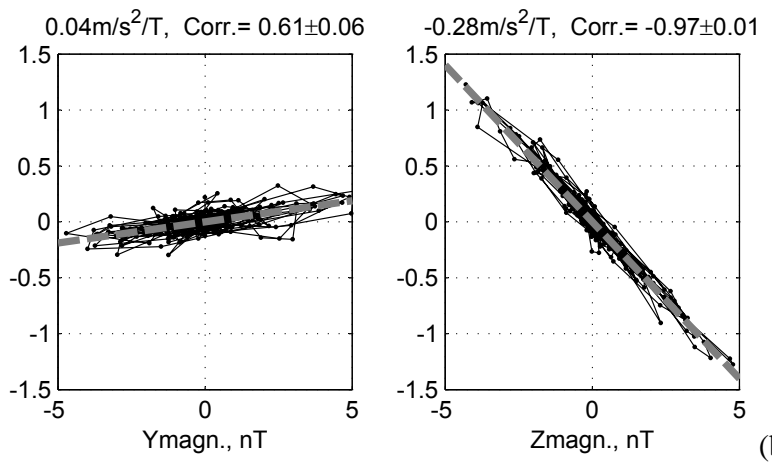

(b)

Fig. 12. (a) Result of the multi-factor analysis for the case of Pc4 pulsations recorded in Kilpisjärvi. Each panel shows correlation of the signal at Z-component of the STS-2 seismometer with one of the three components of the magnetic field. (b) Same as Fig. 11, but for the case of Pi2 pulsations observed in Kilpisjärvi on 26 July 2007.

geomagnetic pulsations observed in Kilpisjärvi and shown in Fig. 11a and b, respectively. Figure 13c shows the amplitude ratio of seismic-to-magnetic signal corresponding to the $K_{z z}$ coefficients calculated for different frequencies. The ratios are shown only for the spectral components at which amplitudes of magnetic signal exceed a noise level of $0.2 \mathrm{nT}$.

One can see that the obtained ratios are close to the regression coefficients $\left(0.28\right.$ and $0.27 \mathrm{~m} \mathrm{~s}^{-2} \mathrm{~T}^{-1}$ for the Pi2 and Pc4 pulsations, respectively) calculated above. The Pi2 pulsations have a multi-component spectral composition, which makes it possible to observe the seismometer response to magnetic disturbances in a range of frequencies from 5 to $17 \mathrm{mHz}$. One can notice that $K_{z z}$ increases with frequency. This dependence on frequency may be approximated by a linear regression, similar to that observed in Sodankylä station on 10 August 2006 (Figs. 2-5). However, the value of the regression coefficient is smaller (4.5 vs. 16).

Indeed, it is necessary to notice that the coefficients calculated for co-located magnetometer and seismometer at Kilpisjärvi station (averaged $0.28 \mathrm{~m} \mathrm{~s}^{-2} \mathrm{~T}^{-1}$, and regression $4.5 \mathrm{~m} \mathrm{~s}^{-1} \mathrm{~T}^{-1}$ ) differ from those estimated for instruments at Sodankylä station (averaged $0.17 \mathrm{~m} \mathrm{~s}^{-2} \mathrm{~T}^{-1}$, and regression $16 \mathrm{~m} \mathrm{~s}^{-1} \mathrm{~T}^{-1}$ ), although both stations are equipped with the instruments of the same types. This may indicate that the effect of magnetic disturbances on broadband seismometer is dependent also on local conditions at the seismometer site.
The local conditions are defined mainly by presence of ferromagnetic materials with high magnetic permeability (for example, iron doors and iron-concrete vault) and also by different conductivity of the subsurface. It is known that variation of geomagnetic field observed at any site on the Earth is a sum of external field caused by magnetospheric and ionospheric currents and the field induced by these currents in the Earth. That is why the amplitude, phase and direction of the geomagnetic field at two different sites would be dependent also on conductivity of the subsurface (see, for example Lilley, 1991; Viljanen et al., 1995). In particular, the magnetometer and seismometer at Sodankylä station are located at a distance of about $11 \mathrm{~km}$ from each other. The seismometer is installed inside the cellar with iron-concrete walls and iron door and there is a nearby outcrop of black schists with high content of graphite. That is why the geomagnetic field measured at the SOD site differs slightly from that at the SGF site.

\section{Discussion and conclusions}

In our study we demonstrated that geomagnetic pulsations (ULF waves) can seriously affect recordings of the STS-2 force-balanced broadband seismic sensor. Hovewer, the effect could be significant for all seismic sensors based on the 
a)

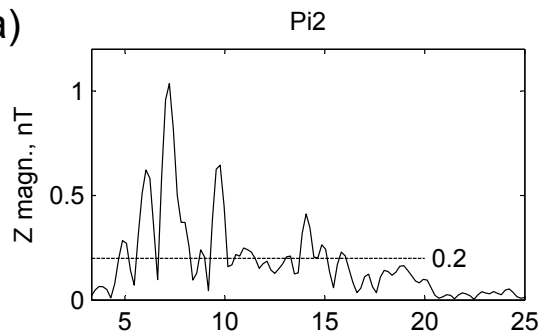

b)

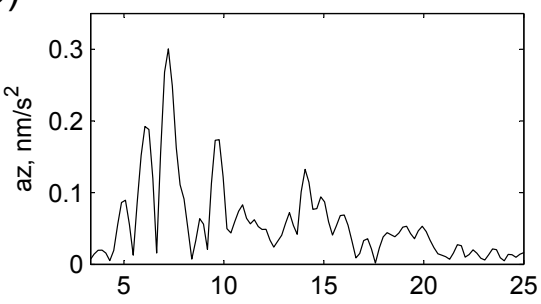

c)

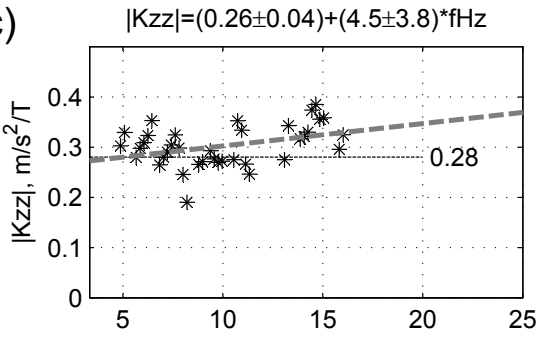

d)

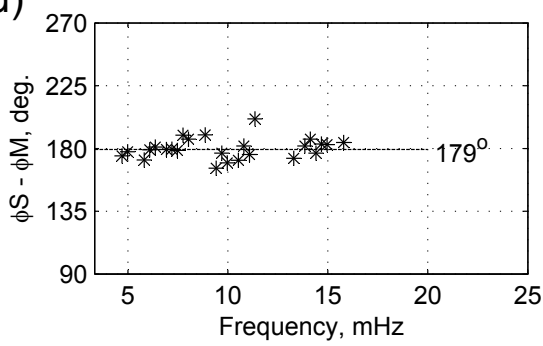

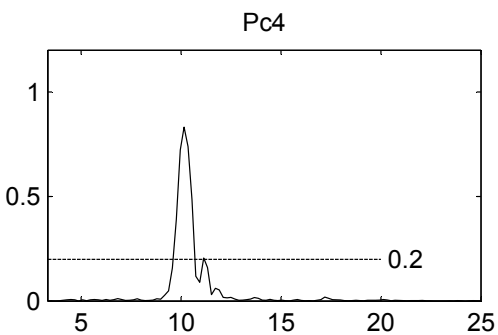
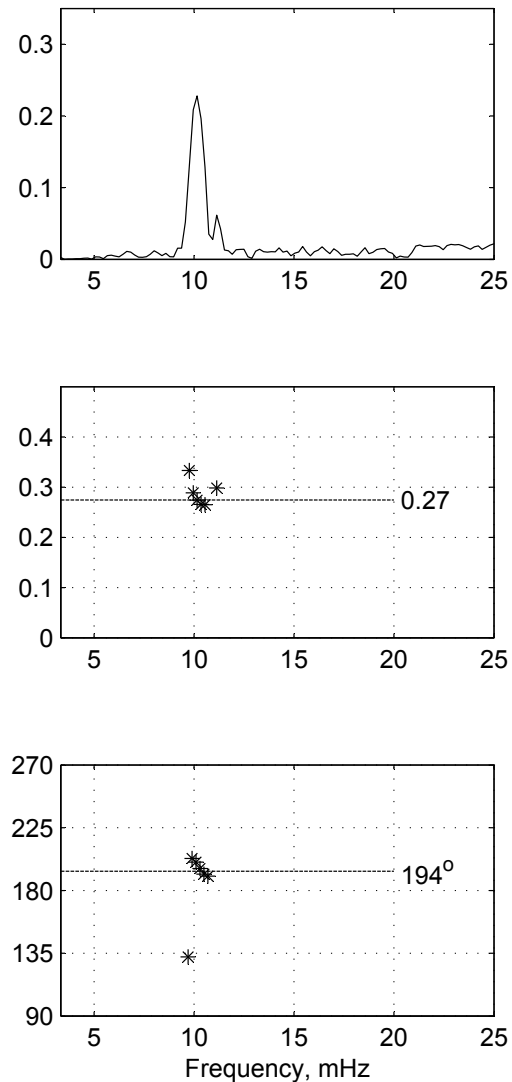

Fig. 13. Amplitude spectra of the magnetic (top panels) and seismic (the second row from the top panels) signals in $Z$-component for the cases of Pi2 (on the left) and Pc4 (on the right) geomagnetic pulsations observed in Kilpisjarvi. The third row from the top panels (c) shows the amplitude ratio of seismic-to-magnetic signals, which corresponds to the Kzz coefficients calculated for different frequencies. The ratios are shown only for the spectral components at which amplitudes of magnetic signal exceed a noise level of $0.2 \mathrm{nT}$. The bottom panels show the phase shift (near $180^{\circ}$ ) between seismic and magnetic signals.

same principle. For example, Forbriger et al. (2010) demonstrated that Trillium 240 seismometer is sensitive to longperiod (about $1 \mathrm{~h}$ ) magnetic disturbances during magnetic storm, although they did not consider the particular effect of geomagnetic pulsations. The effect of geomagnetic pulsations on the Guralp CMG-3T and Trillium 240 sensors was observed in Antarctica (D. Wiens, personal communication, 2009). The influence of the geomagnetic pulsations on the Trillium 120PA sensor was observed also by the authors at the site of a new seismic station in Lapland. From these disturbances, regular Pc3-4 and irregular Pi2 pulsa- tions can create problems for proper interpretation of seismic observations (in particular, glacial earthquakes) in the auroral regions. As the number of seismic observations in Polar Regions has increased drastically during the recent International Polar Year 2007-2009, the problem cannot be just ignored. The influence of geomagnetic pulsations on broadband seismometers deployed in Polar Regions depends on the position of the station with respect to the geomagnetic latitude and can vary significantly within several hundreds of kilometres.

Reasons for the magnetic field influence on broadband seismometers seem to be not completely understood. In our 
study we proposed that sensitivity of the STS-2 seismometer to the variations of geomagnetic field in the frequency range corresponding to geomagnetic pulsations may be due to the currents induced by this field in the feedback coil of the electromagnetic force transducer. Force transducers of this type are known to be sensitive to surrounding magnetic field, unless they are properly shielded (Brauer, 2006; Webster, 2000), and this property limits their usage in some technical applications. For example, such transducers cannot be used in medical robots operating in a magnetic resonance imaging environment (Brock et al., 2009).

Influence of geomagnetic field on broadband seismometers can be considered as a special case of a more common phenomenon connected with influence of geomagnetically induced currents (GIC) on electric and electronic systems. This phenomenon has been well known since the 19th century when the effect of these currents on oil pipes and telegraph lines was first noticed. Because of the Faraday law, the geomagnetic field induces currents in every closed circuit of any electric and electronic system on the Earth, in particular if the circuit contains a coil. If the own currents in the system are large enough compared to the GIC, then the effect of GIC would be small and performance of the system would not be affected. But in modern electronic systems there is a tendency that the currents become smaller, thus the problem of GIC is nowadays relevant not only for oil pipes, but also for electronic devices (in particular, for those operated in auroral regions). As broadband seismometers are electronic systems nowadays, they are not excluded from this common rule.

Although direct influence of the magnetic field on the electromagnetic force transducers is a universal mechanism explaining sensitivity of force balanced seismometers to variations of geomagnetic field, this influence was not considered in the previous studies by Forbriger (2007) and Forbriger et al. (2010) who suggested the needle effect as the most effective. Our study shows that, indeed, the needle effect might be the major factor responsible for sensitivity of the STS-2 seismometer in Kilpisjärvi (Fig. 13); however it fails to explain the frequency dependence of the same type instrument in Sodankylä (Fig. 5). The later might be due to the induced electric field in according with the Faraday law.

Another argument in favour of different mechanisms is the fact that gravimeters and strainmeters, having suspensions with similar properties, are not so sensitive to the variations of magnetic field as broadband seismometers (Pálinkás et al., 2003; Forbriger, 2007). Forbriger (2007) also noticed that different types of seismic sensors have different sensitivity to the variations of the magnetic field. These differences in sensitivity of different sensors to magnetic field can hardly be due to the variations in magnetic properties of suspensions only.

For reducing the magnetic field inducing noise, passive and active magnetic shielding methods were proposed (Wielandt, 2002a, b). An active compensation consisting of a three-component magnetometer that senses the field near the seismometer, an electronic driver circuit in which the signal is integrated with a short time constant (a few milliseconds), and a three-component set of Helmholtz coils which compensate changes of the magnetic field (Wielandt, 2002a) were proven to be efficient at the permanent station STU (Stuttgardt) of the networks GRSN and GEOFON. Although effective at a permanent observatory, this system can hardly be used in temporary installations under hard field conditions, in particular at remote sites in polar regions. One more problem for active compensation may arise due to the fact that magnetometers are to some degree sensitive to seismic noise (Pedersen, 1987). Passive shields can be manufactured from permalloy ( $\mu$-metal), but they are expensive and of limited efficiency for ULF magnetic field variations (Ludvig, 1973; Wielandt, 2002b).

Our study demonstrated that the problem may be also treated if seismic broadband sensors and magnetometers are co-located and combined analysis of seismic and magnetic recordings is used. In many cases, existing magnetometer networks can be easily utilised for that. Several circumstances need to be taken into account, however:

- As the magnetic disturbances are caused by the ionospheric currents at a height of about $100 \mathrm{~km}$, the distance between co-located instruments must be essentially smaller than that. Practically, it must be less than $30 \mathrm{~km}$.

- Obviously, the seismometer containing magnetic materials cannot be installed exactly at the same location as the magnetometer. The local conditions (namely, ferromagnetic materials in a vicinity of the seismometer) may be different, so the set of correlation coefficients (Eqs. 5 and 6) is generally unique for each pair of colocated instruments. The coefficients can be inferred from simultaneous observations using the technique described in Sect. 5.

- The correlation coefficients may be frequencydependent even within a relatively narrow frequency band. In principle, the frequency characteristics could be inferred from long enough timeseries of observations.

- We have not observed an essential phase difference between responses of the STS-2 seismometers and magnetometers at the sites considered in our study. However, this needs to be checked for each particular pair of instruments located at any particular site.

Usage of a co-located magnetometer is obviously cheaper than active or passive shielding and can be easily implemented at existing remote sites in Polar Regions.

Another solution can be the development of new types of seismic sensors without electromagnetic force transducers. 
Acknowledgements. This study was made within the International Polar Year 2007-2009. The seismic data of the Kilpisjärvi (KIF) station of the Institute of Seismology of the University of Helsinki was used. We thank the Finnish Meteorological Institute and other institutes who maintain the IMAGE magnetometer array. We thank Kari Pajunpää for help in processing geomagnetic data. Work of Alexander Kozlovsky at the Sodankylä Geophysical Observatory was funded by the Academy of Finland grant 115920 . We are thankful to Douglas Wiens for his constructive comments concerning performance of broadband seismometers in Antarctica.

Edited by: L. Vazquez

\section{References}

Block, B. and Moore, R. D.: Measurements in the earth mode frequency range by an electrostatic sensing and feedback gravimeter, J. Geophys. Res., 71, 4361-4375, 1966.

Brauer, J. R.: Magnetic actuators and sensors, IEEE Press, John Wiley and Sons, Inc., Hoboken, New Jersey, 2006.

Brekke, A., Feder, T., and Berger, S.: Pc4 giant pulsations recorded in Tromso, 1929-1985, J. Atmos. Terr. Phys., 49, 1027-1032, 1987.

Brock, O., Trinkle, J., and Ramos, F. (Eds.): Robotics: Science and Systems IV. Papers presented at Robotics: science and systems 2008, held at the Swiss Federal Institute of Technology (ETH) Zürich, Switzerland, 25-28 June 2008, Massachusetts Institute of Technology, 2009.

Chisham, G. and Orr, D.: The association between giant pulsations (Pgs) and the auroral oval, Ann. Geophys., 12, 649-654, doi:10.1007/s00585-994-0649-4, 1994.

Ekström, G.: Global detection and location of seismic sources by using surface waves, B. Seismol. Soc. Am., 96, 1201-1212, 2006.

Ekström, G., Netless, M., and Abers, G. A.: Glacial earthquakes, Science, 302, 622-624, doi:10.1126/science.1088057, 2003.

Ekström, G., Netless, M., and Tsai, V.: Seasonality and Increasing Frequency of Greenland Glacial Earthquakes. Science, 311, 1756, doi:10.1126/science.1122112, 2006.

Engebretson, M. J., Posch, J. L., Pilipenko, V. A., and Chugunova, O. M.: Ground based observations of ULF waves at high latitudes, in: Magnetospheric ULF Waves: Synthesis and New Directions, Geophysical Monograph 169, edited by: Takahashi, K., Chi, P. J., Denton, R. E., and Lysak, R. L., American Geophysical Union, Washington, D.C., 137-156, 2006.

Forbriger, T.: Reducing magnetic field induced noise in broad-band seismic recordings, Geophys. J. Int., 169, 240-258, 2007.

Forbriger, T., Widmer-Schnidrig, R., Wielandt, E., Hayman, M., and Ackerley, N.: Magnetic field background variations can limit the resolution of seismic broad-band sensors, Geophys. J. Int., 183, 303-312, doi:10.1111/j.1365-246X.2010.04719.x, 2010.

Gul'elmi, A. V.: Diagnostics of the magnetosphere and interplanetary medium by means of pulsations, Space Sci. Rev., 16, 331345, 1974.

Gustafsson, G., Papitashvili, N. E., and Papitashvili, V. O.: A Revised Corrected Geomagnetic Coordinate System for Epochs 1985 and 1990, J. Atmos. Terr. Phys., 54, 1609-1631, 1992.

Jacobs, J. A.: Geomagnetic micropulsations, Springer Verlag, Berlin, 1970.
Jacobs, J. A., Kato, Y., Matsushita, S., and Troitskaya, V. A.: Classification of geomagnetic micropulsations, J. Geophys. Res., 69, 180-181, 1964.

Janovsky, B. M.: Geomagnetism, Izdat Leningrad. Univ., Leningrad, 1978.

Lilley, F. E. M.: Electrical conductivity anomalies in the Australian lithosphere: effects on magnetic gradiometer surveys, Explor. Geophys., 22, 243-246, 1991.

Ludvig, H. W.: Shielding effect of materials in the ULF, ELF and VLF region, Int. J. Biometeorol., 17, 207-211, 1973.

McPherron, R. L.: Magnetic pulsations: Their sources and relation to solar wind and geomagnetic activity, Surv. Geophys., 26, 545592, 2005.

Nettless, M. and Ekström, G.: Glacial earthquakes in Greenland and Antarctica, Annu. Rev. Earth Pl. Sc., 38, 465-489, 2010.

Nikitin, A. A.: Probability and statistical methods of treatment and interpretation of the results of geophysical observations, in: Reference book on computing mathematics and techniques in the exploration geophysics, edited by: Dmitriev, V. I., Nedra, Moscow, 235-339, 1990.

Pálinkás, V., Kaspar, V., and Lederer, M.: Effect of the magnetic field on LCD gravimeters, in: Proceedings of the Workshop: IMG-2002 Instrumentation and metrology in gravimetry, edited by: Francis, O. and van Dam, T., ECGS and BIPM, Münsbach, Grand-Duchy of Luxembourg, 2003.

Parkinson, W. D.: Introduction to geomagnetism, Scottish Academic Press, Edinburgh, London, 433 pp., 1983.

Pedersen, L.: Some aspects of magnetotelluric field procedures, Surv. Geophys., 9, 245-257, 1987.

Peterson, J.: Observations and modeling of background seismic noise, Open-file report 93-322, US Geological Survey, Albuquerque, New Mexico, 1993.

Pilipenko, V. A., Chugunova, O. M., and Engebretson, M. J.: Pc34 ULF waves at polar latitudes, J. Atmos. Sol.-Terr. Phys., 70, 2262-2274, 2008.

Rostoker, G., Akasofu, S.-I., Foster, J., Greenwald, R. A., Kamide, Y., Kawasaki, K., Lui, A. T. Y., McPherron, R. L., and Russell, C. T.: Magnetospheric substorms - Definition and signatures, J. Geophys. Res., 85, 1663-1668, 1980.

Streckeisen, G.: Portable very-broad-band tri-axial seismometer STS-2, Manual (serial number 20528), G. Streckeisen AG, Messgeräte, Switzerland, 1995.

Troitskaya, V. A. and Gul'elmi, A. V.: Geomagnetic Micropulsations and Diagnostics of the Magnetosphere, Space Sci. Rev., 7, 689-768, 1967.

Viljanen, A., Kauriste, K., and Pajunpää, K.: On induction effects at EISCAT and IMAGE magnetometer stations, Geophys. J. Int., 121, 893-906, 1995.

Webster, J. G. (Ed.): The measurement, instrumentation and sensors, CRC Press Ltd. and Springer Verlag Gmbh, Heidelberg, Germany, 2000.

Wielandt, E.: Seismic sensors and their calibration, in: New Manual of Seismological Observatory Practice, edited by: Bormann, P. and Bergmann, E., GeoForschungsZentrum Potsdam, Germany, $2002 \mathrm{a}$.

Wielandt, E.: Seismometry, in: International Handbook of Earthquake and Engineering Seismology, Vol. A, edited by: Lee, W. H. K., Kanamori, H., Jennings, P. C., and Kisslinger, C., Academic Press, Amsterdam, 283-304, 2002b. 
Wielandt, E. and Streckeisen, G.: The leaf-spring seismometer: design and performance, B. Seismol. Soc. Am., 72, 2349-2367, 1982.

Wiens, D. A., Anandakrishnan, S., Winberry, J. P., and King, M. A.: Simultaneous teleseismic and geodetic observations of the stickslip motion of an Antarctic ice stream, Nature, 453, 770-774, doi:10.1038/nature06990, 2008.
Yumoto, K.: Characteristics of Pi 2 magnetic pulsations observed at the CPMN stations: A review of the STEP results, Earth Planet. Space, 53, 981-992, 2001. 